\title{
Absence of a generalization decrement in the poison-induced avoidance of interoceptive stimuli in the rat
}

\author{
DENIS MITCHELL, LORNE F. PARKER, and ROBERT JOHNSON \\ University of Washington, Seattle, Washington 98195
}

\begin{abstract}
Rats poisoned either immediately or $4 \mathrm{~h}$ after consuming one novel solution were subsequently tested with either a water vs. the conditioned novel solution choice or with a water vs. a second unconditioned novel solution choice. The results showed that: (1) there was a significant avoidance of both solutions by the immediately poisoned groups compared to their respective controls, and (2) there was a clear avoidance of the unconditioned novel solution and a marginal avoidance of the conditioned novel solution by the 4 -h poisoned groups compared to their respective controls. The absence of a generalization decrement indicates that associative mechanisms such as stimulus generalization cannot adequately account for these results. An alternative explanation, based on the interaction of associative mechanisms with the habituation and sensitization of neophobia is proposed.
\end{abstract}

The novelty of the substance paired with poisoning is of considerable importance in the poison-induced avoidance behaviors of the rat (Mitchell, Hoch, \& Fitzsimmons, 1975; Mitchell, Kirschbaum, \& Perry, 1975; Revusky \& Bedarf, 1967; Richter, 1953; Wittlin \& Brookshire, 1968). For example, Rzóska (1953) has shown that when rats are poisoned after consuming one novel food, the survivors will subsequently avoid other novel foods as well. This behavior has been attributed to either the generalization of a learned taste aversion (Domjan, 1975; Nachman, 1963; Tapper \& Halpern, 1968) or to a sensitization of the rats' neophobia or innate fear of novel stimuli (Mitchell, Hoch, \& Fitzsimmons, 1975; Mitchell, Kirschbaum, \& Perry, 1975; Rozin, 1968). Mitchell, Kirschbaum, and Perry (1975) recently reported that rats poisoned after eating from a familiar food source showed a slightly greater avoidance of a novel food source than rats poisoned after eating from the novel food source itself. Though only exteroceptive stimuli were used, the absence of a generalization decrement (Deese \& Hulse, 1958) suggests that the greater avoidance of the unconditioned novel food source by the rats poisoned after eating from the familiar food source cannot be explained entirely in terms of exteroceptive stimulus generalization. The purpose of the present experiment was to determine if the rats' poison-induced avoidance of a second novel interoceptive stimulus (a flavored solution) is

Supported in part by Grant 63-0614 from the University of Washington Alcoholism and Drug Abuse Institute awarded to Lorne F. Parker. We wish to thank Linda Mitchell and Paul Kulkosky for their technical assistance. Requests for reprints should be sent to Denis Mitchell, Department of Psychology, University of Washington, Seattle, Washington 98195. analogous to the poison-induced avoidance of exteroceptive stimuli.

\section{METHOD}

Thirty naive male Wistar rats, approximately 120 days old and obtained from the colony maintained by the Department of Psychology of the University of Washington, were used as subjects. All subjects were individually housed in stainless steel cages and maintained on ad-lib Purina Lab Chow throughout the experiment. For the first 2 days after housing, tap water was also provided ad lib from glass water bottles equipped with stainless steel spouts attached to the front of each cage. The rats were then adapted to a restricted water regimen in which access to water was limited to a $30-\mathrm{min}$ period at the same time each day. The animals were maintained on this schedule for 8 days, by which time all subjects were consuming at least $20 \mathrm{ml}$ of water during each fluid session. The position of the water bottles was alternated daily from the left to the right side of the cages during this portion of the experiment.

Eleven days after housing, the animals were weighed and randomly assigned to one of three treatment groups $(\mathrm{n}=10$ /group). Subjects in all groups were then given access to a $.1 \%(\mathrm{v} / \mathrm{v})$ almond flavored (Schilling's extract) solution during the usual 30-min fluid session. Immediately following the fluid session, subjects in Group $\mathrm{O}$ were made ill by administration of an intraperitoneal injection of $.15 \mathrm{M}$ lithium chloride $(2 \mathrm{ml} / 100 \mathrm{~g}$ body weight). Control subjects in Group $\mathrm{C}$ were treated identically except that they were injected with an equivalent volume of isotonic saline. Subjects in Group 4 were poisoned with equivalent doses of $\mathrm{LiCl} 4 \mathrm{~h}$ after the session.

On the following day, a two-bottle preference test was administered to all animals during the usual fluid session. Subjects in each treatment group were randomly assigned to one of two test conditions ( $n=5 /$ test condition); half of the animals received access to both water and the almond solution, the other half received access to water and a $.1 \%(\mathrm{v} / \mathrm{v})$ maple flavored (Schilling's extract) solution. For half of the subjects, the water bottle was initially placed on the right; for the other half, it was initially placed on the left. Thereafter, the left-right positions of the test solutions were alternated every $10 \mathrm{~min}$ during the 30 -min preference test. This procedure insured that all subjects sampled both fluids. Consumption of water and almond or maple solutions during the 30-min preference test was recorded for each subject. 


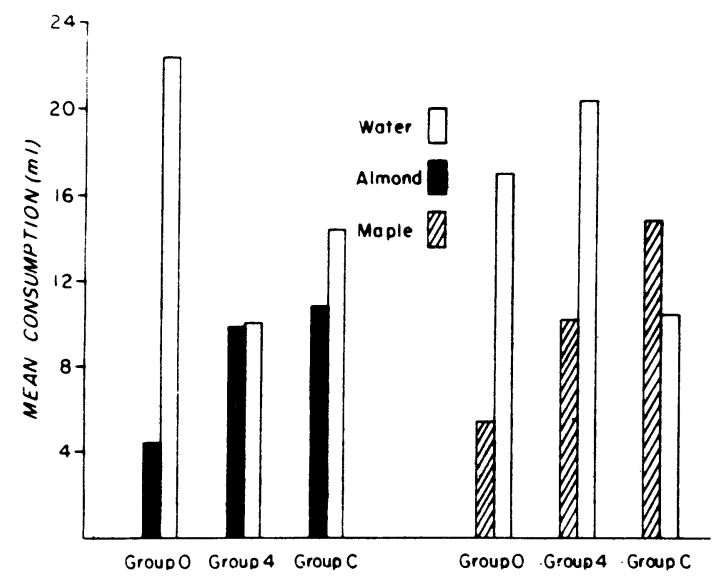

Figure 1. Mean consumption of water and almond or maple solution on the day following the pairing of almond consumption with toxicosis.

\section{RESULTS}

As indicated in Figure 1, the rats that were poisoned immediately after consuming the almond solution (Group 0 ) equally avoided both the almond and maple solutions on the following day. However, the rats poisoned $4 \mathrm{~h}$ after consuming the almond solution (Group 4) showed a greater avoidance of the unpaired maple solution than they did of the almond solution which had been paired with toxicosis on the preceding day.

An analysis of variance applied to the almond and maple consumption scores showed that there were significant differences in consumption of the flavored solutions among the groups $[F(5,29)=3.88$, $\mathrm{p}<.01]$. Individual comparisons between the six groups made with Fisher's significant difference test revealed that any difference between consumption means greater than $3.7 \mathrm{ml}$ was significant to the .05 level $[\mathrm{t}(24)=2.06$, two-tailed]. As depicted in Figure 1, Group 4 subjects tested with the maple test solution consumed significantly less maple than the subjects in Group C tested with maple. The Group 4 subjects tested with the almond, on the other hand, did not consume significantly less almond than the corresponding subjects in Group C when these differences in almond consumption were evaluated with a two-tailed test. Thus, testing the poisoned animals with a second novel solution produced an avoidance that was as great as (Group 0 ), or greater than (Group 4), the avoidance of the novel solution paired with toxicosis. It is particularly noteworthy that a "delay of reinforcement gradient" was more apparent in the avoidance behavior of subjects tested with the unconditioned maple solution than in subjects tested with the conditioned almond solution.

\section{DISCUSSION}

It has been well established that poisoning contingent upon the consumption of a novel substance increases the subsequent avoidance of that substance (see Garcia \& Ervin, 1968; Revusky \& Garcia, 1970; Rozin \& Kalat, 1971, for reviews). It has also been well established that habituation to a specific novel stimulus decreases the subsequent avoidance of that stimulus (see Harris, 1943; Humphrey, 1933; Thorpe, 1963, for reviews). In the present experiment, the almond solution used as the conditioned stimulus was also the habituated stimulus.

Most models designed to explain the poison avoidance behavior of the rat (Domjan, 1975; Garcia \& Ervin, 1968; Nachman \& Jones, 1974; Revusky \& Garcia, 1970; Rozin \& Kalat, 1971; Seligman, 1970) are based on the assumption that this behavior is primarily due to associative learning mechanisms. A pertinent characteristic of both classically and instrumentally acquired associations is that the conditioned response is not limited to the stimulus to which it was originally conditioned, but generalizes to other related stimuli as well. For example, one might interpret the present results as due to the initial formation of a conditioned taste aversion to the first novel solution followed by a subsequent generalization to the second novel solution. However, when one considers that a generalization decrement is a salient property of the generalization process (Deese \& Hulse, 1958, p. 171), it becomes apparent that the absence of such a decrement in the present results argues against the primacy of associative factors.

We have suggested elsewhere (Mitchell, Hoch, \& Fitzsimmons, 1975; Mitchell, Kirschbaum, \& Perry, 1975) that a two-process model which includes both conditioning and habituation can more readily explain the poison avoidance behavior of the rat. Briefly, the model assumes that rats are neophobic; they show an innate fear of novel stimuli. Over time, a given stimulus loses its avoidance-eliciting properties through a process of habituation. When conditioning procedures are used, they are superimposed upon the fundamental habituation process which is occurring simultaneously. In this view, the complex poison avoidance behavior of the rat is due to an interaction between the habituation of an innate behavior, neophobia, and associative-learning mechanisms.

Applied to the present results, the habituationconditioning model would predict that procedures designed to enhance the effectiveness of conditioning (close temporal pairing of the almond solution with toxicosis-Group 0) are more likely to insure the formation of a specific association. Whereas less effective conditioning procedures (delayed pairing of the almond solution with toxicosis-Group 4) are more likely to insure the sensitization of an innate 
neophobia and to produce a greater avoidance of the relatively more novel maple solution than of the almond solution which has been made less novel by prior exposure some hours before poisoning. This model is in essential agreement with Nachman's (1970) suggestion that the longer the interval between the consumption of a novel substance and poisoning, the more likely it is that subsequent poison-induced avoidance behavior is due to an enhanced neophobia rather than to purely associative factors.

\section{REFERENCES}

DeEse, J., \& Hulse, S. H. The psychology of learning. New York: McGraw-Hill. 1958.

Domjan, M. Poison-induced neophobia in rats: Role of stimulus generalization of conditioned taste aversions. Animal Learning \& Behavior, 1975, 3, 205-211.

GARCIA, J., \& ERVIN, F. R. Gustatory-visceral and telereceptor cutaneous conditioning-adaptation in internal and external milieus. Communications in Behavioral Biology, 1968, 1(Part A), 389-415.

HARRIS. J. D. Habituatory response decrement in the intact organism. Psychological Bulletin, 1943, 40, 385-422.

Humphrey, G. The nature of learning. New York: Harcourt. Brace. 1933.

Mitchell, D. Hoch, N. E., \& Fitzsimmons, M. Effects of neophobia sensitization on the rat's preference for earned food. Behavioral Biology, 1975, 13, 519-525.

Mitchell. D., Kirschbaum, E. H., \& Perry, R. L. Effects of neophobia and habituation on the poison-induced avoidance of exteroceptive stimuli in the rat. Journal of Experimental Psychology: Animal Behavior Processes, 1975, 104, 47-55.

NaChMan, M. Learned aversion to the taste of lithium chloride and generalization to other salts. Journal of Comparative and Physiological Psychology, 1963, 56, 343-349.
NaChman, M. Learned taste and temperature aversions due to lithium chloride sickness after temporal delays. Journal of Comparative and Physiological Psychology, 1970, 73, 22-30.

Nachman, M., \& Jones, D. R. Learned taste aversions over long delays in rats: The role of learned safety. Journal of Comparative and Physiological Psychology, 1974, 86, 949-956.

Revusky, S. H., \& BedarF, E. W. Association of illness with prior ingestion of novel foods. Science, 1967, 155. 219-220.

REVUSKY, S. H., \& GaRCIA, J. Learned associations over long delays. In G. H. Bower \& J. T. Spence (Eds.), The psychology of learning and motivation: Advances in research and theory. New York: Academic Press, 1970.

Richter, C. P. Experimentally produced behavior reactions to food poisoning in wild and domesticated rats. Annals of the New York Academy of Science, 1953, 56, 225-239.

Rozin, P. Specific aversions and neophobia resulting from vitamin deficiency or poisoning in half-wild and domestic rats. Journal of Comparative and Physiological Psychology, 1968, 66, 82-88.

Rozin, P., \& Kalat, J. W. Specific hungers and poison avoidance as adaptive specializations of learning. Psychological Review, 1971, 78, 459-486.

Rzoska, J. Bait shyness, a study in rat behaviour. British Journal of Animal Behaviour, 1953, 1, 128-135.

Seligman, M. E. P. On the generality of the laws of learning. Psychological Review, 1970, 77, 406-418.

TAPPER, D. N., \& Halpern, B. P. Taste stimuli: A behavioral categorization. Science. 1968, 161, 708-710.

TновPE, W. H. Learning and instinct in animals. London: Methuen, 1963.

Wittlin, W. A., \& Brookshire, K. H. Apomorphine-induced conditioned aversion to a novel food. Psychonomic Science, 1968. 12, 217-218.

(Received for publication July 20, 1975; revision accepted September 30, 1975.) 